\title{
Distribution and fate of HIV-1 unintegrated DNA species: a comprehensive update
}

\author{
Faysal Bin Hamid, Jinsun Kim and Cha-Gyun Shin ${ }^{*}$
}

\begin{abstract}
Reverse transcription of viral RNA and the subsequent integration of reverse transcripts are the classical early events of the HIV-1 life-cycle. Simultaneously, abundant unintegrated DNAs (uDNAs), are formed in cells ubiquitously. The uDNAs either undergo recombination or degradation or persist inactively for long periods in the nucleus as future resources. Among them, 2-LTR circles are considered a dead-end for viral spread. Their contribution to the HIV-1 infection is still poorly understood. Nevertheless, the preintegration transcription of the aberrant DNAs and the consequent alterations of cellular factors have already been reported. Since the major fate of the viral genome is to persist as episomal DNA, precise characterization is required for studying the biology of HIV-1. This review compiles the biochemical and genetic updates on UDNA in the HIV-1 life cycle and could provide direction to further study of their roles in HIV-1 replication and application in HIV-1 pathogenesis.
\end{abstract}

Keywords: Retrovirus, HIV-1, Nuclear import, 2-LTR, Unintegrated DNA

\section{Background}

Conversion of single-stranded RNAs to linear doublestranded reverse transcripts and their subsequent integration into host chromosomes are signature features of the early stage of the human immunodeficiency virus (HIV) lifecycle [1, 2]. Reverse transcription occurs in the cytoplasm, and the translocation of cDNA to the nucleus gives rise to at least two types of cDNA: linear and circular. Linear cDNA is integrated into host DNA and is transcribed into viral mRNA used in making viral progeny. However, circular forms of viral DNA, containing either one or two copies of the long terminal repeat (LTR) region, accumulate in the infected cells because of abortive integration processes. Although different studies report that they can express a limited range of early genes [3-8], the role of these unintegrated DNAs is still unclear.

Retroviruses enter host cells by endocytosis or by binding to glycoproteins on their surface. Specifically, HIV-1 binds to the receptor CD4 and co-receptors CCR5 and

*Correspondence: chagshin@gmail.com

Department of Systems Biotechnology, Chung-Ang University, Anseong, Kyunggido 456-756, South Korea
CXCR4 on T lymphocytes and macrophages $[9,10]$. After the reverse transcription of viral RNA, which occurs in the endocytosed viral core and uses free cytoplasmic nucleotides and ions, the viral envelope is gradually released in a process known as uncoating [11]. The viral reverse transcripts then bind to at least four viral proteins: matrix (MA), integrase (IN), reverse transcriptase (RT), viral protein (Vpr), and/or capsid (CA), as well as several host proteins. These form a ribonucleoprotein complex, called the pre-integration complex (PIC), which enters the nucleus [10, 12]. After nuclear import, the cDNA either becomes integerated, or fails to integrate and may become circularized to form episomal DNA [3, 13, 14]; circular episomal DNA has in some cases been found in the cytoplasm as well $[15,16]$. Delelis et al. [15] hypothesized that in prototype foamy virus-infected cells, it may be either that the 2-LTR circles formed in the nucleus are unable to be exported into the cytoplasm or that they might be yielded in the cytoplasm and be imported into the nucleus and accumulated. Either of these two events can explain the higher amount of 2-LTR circles detected in the nucleus and their higher stability. 
Although linear DNA is considered as a substrate for provirus production, its ends can also be ligated to form 2-LTR circles by host non-homologous DNA end joining (NHEJ), one of the cellular repair systems. Another form, 1-LTR circles, can result from defective reverse transcription [17], auto-integration from the rearrangement of circular forms $[1,18]$, or homologous recombination between 2-LTR circles [1]. Several proteins of NHEJ have been reported to be involved in this process, such as the Ku70/80 heterodimer, ligase 4, XRCC4, and RAD52 [18-20]. Another type of unintegrated DNA, also known as autointegrants, is formed through the ligation of the internal region of viral DNA to the IN-processed 3 '-end [3, 21-24]. The presence of autointegrants has been confirmed in HIV-1, as well as in other retroviruses, e.g. Moloney murine leukemia virus (MoMLV) and Rous sarcoma virus (RSV) $[1,18,21]$.

\section{Distribution}

After entry into cells, the reverse transcription of HIV-1 RNA occurs in the cytoplasm. Once inside the cytoplasm, viral reverse transcripts form PICs with host proteins. These complexes containing viral double stranded DNA (dsDNA), which has the triple stranded DNA structure called DNA flap, are able to be integrated into the host dsDNA in vitro. This is mediated by IN, which can cleave the $3^{\prime}$-ends of both LTRs of the blunt (or unprocessed) DNA, named linear unintegrated DNA $\left(\mathrm{uDNA}_{\mathrm{L}}\right)$, and results in $3^{\prime}$-processed linear DNA $\left(\mathrm{pDNA}_{\mathrm{L}}\right)$ [25]. The cleavage is occurred by tetrameric IN in case of both palindromic LTR-LTR junction and 2-LTR circle internally [26]. The DNA in PICs may either undergo circularization or remain in the form of linear dsDNA. Munir et al. [27] updated the order of the persistence of viral DNA forms as follows: provirus $>$ circular DNA (1-LTRc and 2-LTRc) $>\mathrm{uDNA}_{\mathrm{L}}>\mathrm{pDNA}_{\mathrm{L}}$. The $\mathrm{pDNA}_{\mathrm{L}}$ is less stable than $\mathrm{uDNA}_{\mathrm{L}}$ and can therefore persist a shorter period than $\mathrm{UDNA}_{\mathrm{L}}$. The HIV-1 infection causes the accumulation of unintegrated DNAs in any cell type or cellular status in vivo $[8,27-29]$ or in vitro [1,30-32] (Table 1). Gene expression from uDNA is higher than integrated proviruses in non-dividing cells compared to dividing cells [14]. The reason is likely due to lack of dilution of uDNA templates, the transcripts and proteins $[3,14,33]$. Interestingly, several groups have shown that the unintegrated circular forms of HIV-1 are present prominently in the nucleus and can be considered as markers of the active transport of the PIC into the nucleus [3, 29, 34]. Avian sarcoma virus was first reported to form circular DNA in infected cells, particularly in the nucleus [35, 36] (Table 1). However, unintegrated DNA was first reported in brain and blood tissue of HIV-1 infected dementia patients [37]. Later, high levels of unintegrated DNA were found in HIV-1 infected cells, both in in vivo on human patients and animals $[38,39]$ and in in vitro experiments on lymphocytic and monocytic cell lines [1,35]. This was expected, as the ratio of linear to 1-LTR circular to 2-LTR circular HIV DNA was previously approximated

Table 1 Examples of unintegrated DNAs in virus-infected cells and their fates

\begin{tabular}{|c|c|c|c|c|c|c|c|}
\hline Virus & Cell line & Cell number & $\begin{array}{l}\text { hpi (hours } \\
\text { per infection) }\end{array}$ & Methods & Consequence & & Ref. \\
\hline Avian sarcoma virus & QT-6 & & 5 hpi & & Closed circular DNA & & {$[34]$} \\
\hline MLV & $\begin{array}{l}\text { NIH 3T3, TE671, } \\
\text { ARPE-19 }\end{array}$ & $1 \times 10^{6}$ cells & 2 hpi & qPCR & 2-LTR & & {$[16]$} \\
\hline \multirow[t]{14}{*}{ HIV-1 } & \multirow[t]{2}{*}{ MT-2 } & \multirow[t]{2}{*}{$5 \times 10^{5}$ cells } & $2 \mathrm{hpi}$ & \multirow{2}{*}{$\begin{array}{l}\text { PCR and Southern } \\
\text { hybridization }\end{array}$} & $1-\mathrm{LTR}$ & & \multirow[t]{4}{*}{ [31] } \\
\hline & & & 12 hpi & & 2-LTR & & \\
\hline & \multirow[t]{2}{*}{ Monocyte } & \multirow[t]{2}{*}{$1 \times 10^{6}$ cells } & $2 \mathrm{hpi}$ & \multirow{2}{*}{$\begin{array}{l}\text { PCR and Southern } \\
\text { hybridization }\end{array}$} & $1-L T R$ & & \\
\hline & & & 12 hpi & & 2-LTR & & \\
\hline & \multirow[t]{2}{*}{ Macrophage } & \multirow[t]{2}{*}{$3 \times 10^{5}$ cells } & $4 \mathrm{dpi}$ & \multirow[t]{2}{*}{ qPCR } & 2-LTR & $\begin{array}{l}30-35 \\
\text { copies/100cells }\end{array}$ & \multirow[t]{4}{*}[45]{} \\
\hline & & & $21 \mathrm{dpi}$ & & & 6 copies/100cells & \\
\hline & \multirow{2}{*}{$\begin{array}{l}\text { CD4+ T lympho- } \\
\text { cytes }\end{array}$} & \multirow[t]{2}{*}{$3 \times 10^{5}$ cells } & 4 dpi & & 2-LTR & 11 copies/100cells & \\
\hline & & & 14 dpi & & & $x$ & \\
\hline & \multirow[t]{2}{*}{ Jurkat } & \multirow[t]{4}{*}{$1 \times 10^{7}$} & \multirow[t]{2}{*}{$3 \mathrm{dpt}$} & & 2-LTR & $8.97 \%$ & \multirow[t]{4}{*}[36]{} \\
\hline & & & & & 1-LTR & $46.21 \%$ & \\
\hline & \multirow[t]{2}{*}{$293 \mathrm{~T}$} & & & & 2-LTR & $5.42 \%$ & \\
\hline & & & & & 1-LTR & $40.16 \%$ & \\
\hline & \multirow{2}{*}{$\begin{array}{l}\text { SupT1 (lymphoid } \\
\text { cells) }\end{array}$} & \multirow[t]{2}{*}{$5 \times 10^{6}$ cells } & 15 hpi & & 2-LTR & 0.01 copy/cell & \multirow[t]{2}{*}[46]{} \\
\hline & & & 12 hpi & & & 40 copies/cells & \\
\hline
\end{tabular}


as 20:9:1 [40, 41]. Interestingly, 1-LTR circles appeared earlier; at approximately at $2 \mathrm{~h}$ post infection (hpi) in HIV-1 infected MT-2 cell lines, while 2-LTR circles were found at about 12 hpi [35]. However, the 2-LTR circles were detected at 1-2 $\mathrm{h}$ hpi in the cytoplasm of murine leukemia virus (MLV)-infected cells [16] and after $72 \mathrm{hpi}$ in prototype foamy virus-infected cells, although they started to accumulate already at $3 \mathrm{hpi}$ in the infected cells [15]. Initially, it was thought that this was due to the lack of cell division in aphidicolin-treated NIH 3T3 cells, but 2-LTR circles also formed in arrested and non-arrested TE671 human medulloblastoma cells and ARPE-19 human retinal epithelial cells [17] (Table 1). It is considered that 1-LTR circles are more abundant than 2-LTR in infected cells both in vitro and in vivo $[42,43]$. The relative abundance is cytoplasmic linear DNA > proviruses $>1$-LTR circles $>2$-LTR circles [42]. However, the autointegration of the HIV-1 genome produces cDNA products either containing nicked, inverted, or modified dsDNA circles [43]. This cytoplasmic DNA is detected by DNA sensors and secreted interferons [23, 44].

In the infected cells, non-integrating HIV-1 and HIV1-based vectors are organized into chromatin structures and enriched with histone modifications typical of silenced chromatins that can be reactivated upon exposure to histone deacetylase (HDAC) inhibitors. [47]. Surprisingly, 1-LTR circles are formed earlier than 2-LTR ones [27]. However, a significant amount, i.e. around $10 \%$, of 1-LTR circles is formed during reverse transcription in the cytoplasm [14, 27]. Kilzer and his colleagues demonstrated that a high level of 1-LTR circles $(90 \%)$ is generated after nuclear import by homologous recombination between two flanked LTR regions of linear DNA and that most of the 1-LTR circles are found in the nucleus [13]. The mechanism of 1-LTR circle formation and the subcellular localization points at its plausible significance in viral replication, mainly in the step of viral integration [27]. The strand-transfer inhibitor raltegravir (RAL) and the catalytic mutation of IN affected $3^{\prime}$-LTR processing differently: the comparison of 2-LTR circle accumulation mediated by either indicated that $3^{\prime}$-end processing has no role in 2-LTR circle accumulation, while the type of the LTR-LTR junction formation is considerably affected. The formation of 2-LTR circles containing original palindromic sequence junctions (40\%) in RAL-treated cells were similar to that in wild type cells, but was nearly doubled in D116N mutants [27]. The pattern of $3^{\prime}$-end processing in circular DNA could be useful in designing the IN-targeting therapeutic agents.

\section{Role of cellular proteins in unintegrated DNA formation} Integration is required for successful retroviral replication. Cellular proteins RAD50, MRE11, and NBS1 are nuclease components that reportedly participate in 1-LTR circle formation [3, 13]. DNA-dependent protein kinase (DNA-PK), a nuclear serine-threonine protein kinase that can phosphorylate downstream proteins after sensing DNA breaks, is essential in the repair of dsDNA breaks by NHEJ. It is composed of a DNA-binding Ku70/ Ku86 heterodimer and a $469 \mathrm{kDa}$ catalytic subunit, DNA$\mathrm{PK}_{\mathrm{cs}}$ [48]. It has a significant role in $\mathrm{V}(\mathrm{D}) \mathrm{J}$ recombination as well. The RAG1/RAG2 proteins generate breaks in the strands of dsDNA. At the break-sites, the Ku70/Ku80 heterodimer binds to the free DNA termini, keeping them localized. DNA-PK ${ }_{\mathrm{cs}}$ binds the DNA-bound Ku to form the DNA-PK complex, which stimulates DNA-PK activity through phosphorylation [49]. It is known that 2-LTR circles are products of DNA repair mechanisms in the nucleus as a host reaction to foreign dsDNA [50]. Viral cDNA replication intermediates have been found to interact with host $\mathrm{Ku}$ components of the NHEJ pathway $[51,52]$. Silencing of the NHEJ components $\mathrm{Ku}$, ligase 4, or XRCC4 decreases the number of 2-LTR circles. Interestingly, the absence of DNA-PKcs, a component of the NHEJ machinery, showed the opposite effect $[13,52]$.

\section{Fate \\ Degradation}

Circular DNAs are considered as replicative dead end. Linear DNA, the substrate of integration, is degraded in dividing $\mathrm{T}$ cells within hours [53], but persists for several days in resting $\mathrm{T}$ cells; it may even persist up to one month in macrophages $[8,54,55]$ (Fig. 1 ). In the pre-integration state, viruses express their genes and produce half of the rescuable virions in resting CD4+ T cells [55]. The shortage of the virus production may be due to the virusinduced programmed cell death (apoptosis) or blockage of reverse transcription. In addition to these fates, in the high-titer infections of cultured cells, the majority of viral DNA undergoes intracellular degradation after synthesis $[41,46,56,57]$. Several further proposals have also been made for DNA repair factors acting on retroviral DNA $[58,59]$.

Highly active antiretroviral therapy (HAART) causes a dramatic reduction in HIV-1 replication during the first 3 years and lowers the level of 2-LTR circles as well [60]. Furthermore, after 7-8 years of uninterrupted therapy, 2-LTR circles were almost undetectable in peripheral blood mononuclear cells (PBMCs) of most of the patients. These observations indicate the labile nature of 2-LTR circles, which may be subject to continuous HAART therapy. However, HIV-1 DNA was still detectable in the infected patients [60], probably due to the ongoing viral replication in newly infected dividing cells. Previously, it was demonstrated that the gradual decrease of the amount of circular DNA in proliferating cells 
occurs due to the absence of an origin of replication and is a function of dilution resulting from cell division [53]. IN mutant-infected macrophages produce DNA that persists at low levels even after 2 weeks, most of which is presumably unintegrated DNA. It was confirmed that the stability of 2-LTR was not due to viral replication [61].

\section{Reservoirs}

Latent unintegrated genomes present in viremic HIV-1 patients after HAART treatment act as reservoirs and are an obstacle to effective treatment. 2-LTR circles persist in HIV-1 infected, growth-arrested $\mathrm{T}$ cell lines beyond their estimated half-life as previously determined in dividing cell populations $[45,56]$. The drop of 2-LTR circle levels in dividing cells might be due to cell division, not due to degradation $[54,62]$. In non-dividing macrophages, the 2-LTR circle levels remained the same for up to 21 days post infection (dpi) (Fig. 1). The unvarying 2-LTR circle level indicates their high stability in macrophages [45]. Moreover, macrophages are resistant to cytopathic effects caused by HIV-1, which makes macrophages a suitable reservoir for further infection $[8,33,45,62]$. This stability in non-replicating cells may be due to their association with host proteins, e.g. histones, which protects them from decay [62]. E-DNA would be diluted out with successive rounds of cell division. In contrast to highlyactive antiretroviral therapy (HAART)-treated HIV-1 patients, elite controllers, a group of HIV-1 infected persons who can control HIV-1 replication naturally in the absence of antiretroviral therapy and maintain untraceable viral loads, had higher 2-LTR circles than integrated proviruses in Ex Vivo experiments [63, 64].

\section{Gene expression}

The integrated HIV-1 provirus is transcribed into new genomic RNA, also serving as mRNA, which is in turn translated into viral proteins [2-6, 65] (Fig. 1). Although it is speculated that the integrated copies of viral DNA are the sole template for viral gene expression, there is also evidence of preintegration transcription from unintegrated DNA [5, 65] (Fig. 1). Most recently, it has been shown that the transcriptional interplay is regulated oppositely between integrated and unintegrated DNA following NF- $\mathrm{KB}$ pathway modulation [66]. Upon various pharmacological treatments of NF- $\mathrm{KB}$ pathway activation, transcription factors such as NF- $\mathrm{kB}$ p65 and AP-1

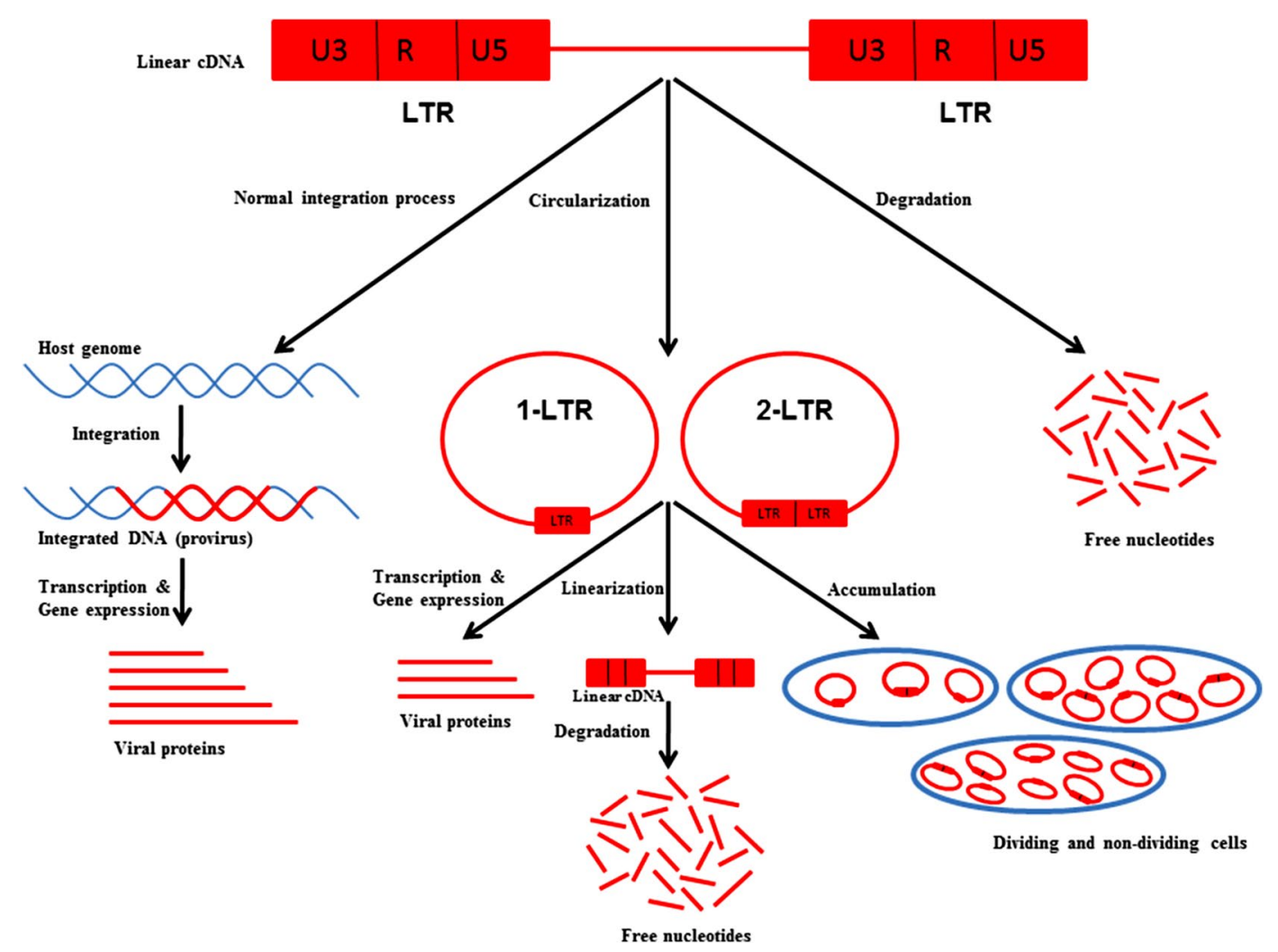

Fig. 1 Fates of viral cDNAs (reverse transcripts) after reverse transcription. After reverse transcription, HIV-1 produces cDNAs that may either be integrated into host genome or circulate themselves. Otherwise, they are degraded into free nucleotides. Circular DNAs have been reported to actively participate in current gene expression similar to the integrated DNAs followed by linearization, degradation, or accumulation as a reservoir 
(cFos/cJun) binds to integrated DNA and increases its expression, though the uDNA expression is declined. On the other hand, inhibition of the NF-kB pathway supports the expression of circular uDNA, and Bcl-3 and AP-1 is associated with its LTR region [66]. However, the persistent expression of HIV-1 proteins has already been reported not only in vitro in non-dividing cells, such as primary rat neurons and growth arrested fibroblasts, and dividing cells, such as SV40 T-antigen expressing cells [67-70], but also in vivo in rodent ocular and brain tissues [69]. Even IN-mutant HIV-1 or integration-arrested viruses produce transcriptionally active circular DNA $[4,5,67,71]$. It is already established that HIV-1 circular unintegrated DNA can promote viral replication itself, but several groups disapproved the notion [40, 47]. Most recently, Shimura et al. [72] reported that the expression of circular DNA genes is possible even after IN strandtransfer inhibitor treatment, probably due to cell-to-cell infection. Particularly, 2-LTR circles can express not only early viral genes, such as $N e f[5,65,72]$, Tat $[40,73]$, and $\operatorname{Rev}[5,40,72]$, but also late, non-spliced, singly- or multiply-spliced transcripts prior to integration. Among them, the Nef and Tat proteins are translated only from the fully spliced mRNA [4]. It has been reported that the expression of circular DNA genes, especially Nef, is augmented by $V p r$ in HIV-1 infected cells [74]. Interestingly, Nef can stimulate $\mathrm{T}$ cell activation and decrease the expression of co-receptors CD4, CXCR4, and CCR5, thus increasing HIV-1 infectivity [75]. In addition, Tat, a transactivator protein of HIV-1, can activate the transcription from LTRs of both unintegrated and integrated viral DNA [76]. Particularly, viral transcripts are expressed from the upstream promoter, probably from the beginning of the $\mathrm{R}$ region located within the tandem LTR repeats of a 2-LTR circle [72]. In non-dividing cells, such as macrophages, gene expression is induced by $\mathrm{Vpr}$ only when it is driven by the HIV-1 LTR promoter, but not by the cytomegalovirus promoter [45]. However, after integration, Rev activity increases in order to support the production of late genes, such as $V p u$, both from spliced and unspliced genes $[5,75]$. Recently, Emeagwali and his colleagues (2012) showed that $V p u$ and the antagonistic host protein TWIK-related acid sensitive $\mathrm{K}+$ channel 1 (TASK1) can preferentially downregulate the transcription of episomal DNA [75]. However, a greater part of nonintegrated viral DNA might be inactive templates for the transcription machinery. When it was observed experimentally, the $\operatorname{Rev}$ transcripts were synthesized from nonintegrated DNA, although the expression level was not high (approximately $0.03-5 \%$ of total viral DNA) and was transient. Inadequate Rev expression was likely the result of the activity of the late structural gene gag in nonintegrated HIV-1 DNA, which was similar to IN defective virus-infected, inhibitor-treated, or quiescent cells [5]. Upon latency reversing agents including PKC activators, histone deacetylase inhibitors and $\mathrm{P}-\mathrm{TEFb}$ agonists) treatment, latent uDNA was reported to initiate lately virus production as well as the latent integrated proviruses [14].

Surprisingly, 2-LTR circles can be used as a substrate for integration by IN and contribute to the spumaviral lifecycle, even after integration [77]. Previously, spleen necrosis virus (SNV), Rous sarcoma virus (RSV), avian sarcoma virus (ASV), and avian leukosis virus (ALV) were assumed to generate the LTR-LTR circles that are used as templates for integration [19, 77]. Generally, IN can cleave the viral double stranded cDNA ends in a staggered manner, which then undergoes covalent transesterification to the $5^{\prime}$ phosphates of the host dsDNA [2, 21]. However, IN also shows the novel pleiotropic action in the mechanism underlying the requirement in the circular DNA integration: it can directly cleave the conserved palindromic sequence found at LTR-LTR junctions and produce linear DNA from 2-LTR circles [77]. Most recently, it has been reported that HIV-1 PIC, specifically IN, can also cleave 2-LTR circles in a similar way [78]. HIV-1 IN required for linearization of 2-LTR circles was found at the palindromic junction, recognized as integration site, and subsequently executed a de novo integration process. It can explain the decrease in the amount of 2-LTR circles and surge of linear DNA, as well as proviral DNA, after the withdrawal of raltegravir in vitro [78] or HAART administration in vivo [39].

Despite the expression level of circular DNA that was reported previously, improved efficiency was observed in the long U3 deletion mutants, both in vivo and in vitro [32]. The U3-region truncation does not alter the diversity of the four types of episomal DNA. Interestingly, the U3 deletion causes high transgene expression from episomes in different levels in non-dividing brain cells and slowly dividing liver cells of rats. The effect of the large U3 deletion on episomal expression indicates that the cisacting elements of the retroviral genome can regulate the extrachromosomal transcriptional activity and that the cell-specific trans-acting factors are presumably implicated in negatively regulated transgene expression from lentiviral episomes [32]. Moreover, the addition of HDAC inhibitors in the form of short-chain fatty acids can also induce gene expression, as well as replication, from episomal DNA. To crosstalk genetically and functionally between integrated and unintegrated DNA, it has been found that HIV-1 gene expression, such as of $V p r$, from unintegrated DNA can be complemented by co-infection with the integrated viral genome $[47,79]$. 
Table 2 Different assays used to measure different analytes

\begin{tabular}{|c|c|c|c|c|}
\hline Analytes & Assays & Advantages & Problems & References \\
\hline Resting CD4+ T cells & PCR & $\begin{array}{l}\text { Considered as 'gold-standard'for } \\
\text { measuring latently infected } \\
\text { cells }\end{array}$ & Low accuracy, slow, costly & {$[28,80]$} \\
\hline Total DNA & $\mathrm{qPCR}$ & $\begin{array}{l}\text { Integrated and unintegrated HIV- } \\
\text { DNA per million in peripheral } \\
\text { blood mononuclear cells } \\
\text { (PBMC) or CD4+ T cells }\end{array}$ & Unknown & {$[80]$} \\
\hline Total HIV-DNA and 2-LTR circles & Droplet digital PCR & $\begin{array}{l}\text { More sensitive and precise com- } \\
\text { paring to real time pol PCR }\end{array}$ & $\begin{array}{l}\text { Short life span of 2-LTR; low } \\
\text { accuracy }\end{array}$ & {$[80]$} \\
\hline Provirus & Alu-gag PCR and qPCR & $\begin{array}{l}\text { Conventional method to detect } \\
\text { integrated proviruses. }\end{array}$ & Nonspecific, low accuracy & {$[80]$} \\
\hline Intracellular HIV-RNA & PCR & $\begin{array}{l}\text { Detection of } 1 \text { copy per million } \\
\text { resting CD4+ T cells }\end{array}$ & Unknown & {$[80]$} \\
\hline Viral RNA & $\begin{array}{l}\text { HIV-RNA single copy assay } \\
\quad(\mathrm{SCA})\end{array}$ & $\begin{array}{l}\text { Ultrasensitive method to quantify } \\
\text { HIV-RNA in plasma }\end{array}$ & Unknown & {$[80]$} \\
\hline
\end{tabular}

\section{Cytocidal effect on host cells}

The cytocidal effect of retroviruses is thought to exist due to the rapid accumulation of unintegrated viral DNA in the cells. The reinfection property might be the reason of cytopathogenesis. Most acutely and chronically infected cells show the cytocidal effect [35]. A lower level of unintegrated DNA indicates that the cells are resistant to superinfection and maintain a persistent infection [35].

\section{Measurement of the HIV-1 reservior and its eradication}

The durable nature of HIV-1 reservoir in all CD4+ T-cell subsets, including naïve and memory cells is a key problem to eradication. The establishment of the pool starts from the very initial time of primary infection associated with cytopathic effect and rounds of new infection. CD4 $+\mathrm{T}$ cells are reported to maintain high levels of HIV DNA even after HAART and it can resume high levels of new replication following ART withdrawal $[64,80]$. However, the samples, the analytes, and the assays must be taken into consideration during the measurement of the reservoir. To date, several assays have been used to measure the different analytes which are considered as the HIV reservoirs (Table 2), but shortage of standardization and validation have made the assessment difficult. The problem of all PCRbased assays is that they can not discriminate between the infectious virion producing cells and latent viral reservoir containg cells (Table 2) [80]. So different real time PCRs have been used to measure the analytes such as viral RNA, 2-LTR and proviruses more accurately. But they are still lack of fidelity of quality and accuracy. Some of the current techniques used to measure the analytes that reflect the HIV-1 reservior have been discussed in Table 2.

\section{Conclusions}

The 2-LTR circles are formed at the initial period of infection in vivo. Most of the cells undergo cell death, while some survive [53] and remain viral reservoirs. The longevity of these cells is due to the "intrinsic stability", which is not identical in all cell types. The viral infection may induce cell survival factors, but the complete molecular mechanisms are still unknown. 2-LTR circles are a clear indication of foregoing viral replication, and the question of using them as valid markers of nuclear import for real time measurement arises [53, 81]. Many groups have reported on the significance of 2-LTR circle gene expression $[3,4,7,8]$, while the mechanisms of formation and gene expression and the fate of 1-LTR is in most cases omitted. The nuclear import of HIV-1 is not dependent on any particular viral or cellular karyophilic proteins $[10,82]$. Since the study of the nuclear import and 2-LTR circles are closely related, the roles of these proteins should be observed more carefully. The complete characterization of the uDNAs might be convenient to understanding the HIV-1 viremia better. Moreover, the pleotropic fate of uDNA renders it a more eligible candidate for gene therapy and drug delivery.

\begin{abstract}
Abbreviations
UDNAs: unintegrated DNAs; HIV: human immunodeficiency virus; LTR: long terminal repeat; MA: matrix; IN: integrase; RT: reverse transcriptase; Vpr: viral protein; CA: capsid; PIC: pre-integration complex; MoMLV: Moloney murine leukemia virus; RSV: Rous sarcoma virus; uDNAL: linear unintegrated DNA; pDNAL: 3'-processed linear DNA; hpi: post infection; MLV: Murine leukemia virus; RAL: raltegravir; DNA-PK: DNA-dependent protein kinase; HAART: highly active antiretroviral therapy; PBMCs: peripheral blood mononuclear cells; dpi: days post infection; TASK1: TWIK-related acid sensitive K+ channel 1.
\end{abstract}

\section{Authors' contributions}

FBH wrote the manuscript and designed the artwork. Both JSK and CGS revised the text and made valuable suggestions. All authors read and approved the final manuscript. 


\section{Acknowledgements \\ None.}

\section{Competing interests}

The authors declare that they have no competing interests.

\section{Funding}

This study was supported by a grant from the National Research Foundation of Korea (NRF), funded by the Korean government (NRF-2015R1D1A1A01059592).

Received: 20 August 2016 Accepted: 7 December 2016 Published online: 16 February 2017

\section{References}

1. Farnet CM, Haseltine WA. Circularization of human immunodeficiency virus type 1 DNA in vitro. JVirol. 1991;65:6942-52.

2. Varmus HE, Brown PO. Retroviruses. In: Berg DE, Howe MM, editors. Mobile DNA. Washington, D.C.: American Society for Microbiology; 1989. p. 53-108.

3. Sloan RD, Wainberg MA. The role of unintegrated DNA in HIV infection. Retrovirology. 2011;8:52

4. Wu Y, Marsh JW. Selective transcription and modulation of resting T cell activity by preintegration HIV DNA. Science. 2001;293:1503-6.

5. Wu Y, Marsh JW. Early transcription from nonintegrated DNA in human immunodeficiency virus infection. J Virol. 2003;77:10376-82.

6. Wu Y. HIV-1 gene expression: lessons from provirus and non-integrated DNA. Retrovirology. 2004;1:13.

7. Wu Y. The second chance story of HIV-1 DNA: unintegrated? Not a problem! Retrovirology. 2008;5:61.

8. Kelly J, Beddall M, Yu D, et al. Human macrophages support persistent transcription from unintegrated HIV-1 DNA. Virology. 2008;372:300-12.

9. Overbaugh J, Miller AD, Eiden MV. Receptors and entry cofactors for retroviruses include single and multiple transmembrane-spanning proteins as well as newly described glycophosphatidyl inositol-anchored and secreted proteins. Microbiol Mol Biol Rev. 2001;65:371-89.

10. Hamid FB, Kim J, Shin CG. Cellular and viral determinants of retroviral nuclear entry. Can J Microbiol. 2016;62:1-15.

11. Lukic Z, Dharan A, Fricke T, et al. HIV-1 uncoating is facilitated by dynein and kinesin 1. J Virol. 2014:88:13613-25.

12. Arhel N. Revisiting HIV-1 uncoating. Retrovirology. 2010;7:96.

13. Kilzer JM, Stracker T, Beitzel B, et al. Roles of host cell factors in circularization of retroviral dna. Virology. 2003;314:460-7.

14. Chan CN, Trinité B, Lee CS, et al. HIV-1 latency and virus production from unintegrated genomes following direct infection of resting CD4 T cells. Retrovirology. 2016:13:1

15. Delelis O, Saïb A, Sonigo P. Biphasic DNA synthesis in spumaviruses. J Virol. 2003:77:8141-6.

16. Serhan F, Penaud M, Petit C, et al. Early detection of a two-long-terminalrepeat junction molecule in the cytoplasm of recombinant murine leukemia virus-infected cells. J Virol. 2004:78:6190-9.

17. Miller MD, Wang B, Bushman FD. Human immunodeficiency virus type 1 preintegration complexes containing discontinuous plus strands are competent to integrate in vitro. J Virol. 1995;69:3938-44.

18. Cara A, Klotman ME. Retroviral E-DNA: persistence and gene expression in nondividing immune cells. J Leukoc Biol. 2006;80:1013-7.

19. Li L, Olvera JM, Yoder KE, et al. Role of the non-homologous DNA end joining pathway in the early steps of retroviral infection. EMBO J. 2001:20:3272-81

20. Lau A, Kanaar R, Jackson SP, et al. Suppression of retroviral infection by the RAD52 DNA repair protein. EMBO J. 2004;23:3421-9.

21. Coffin JM, Hughes SH, Varmus HE. Retroviruses. New York: Cold Spring Harbor Laboratory Press; 1997

22. Shoemaker C, Hoffman J, Goff SP, et al. Intramolecular integration within Moloney murine leukemia virus DNA. J Virol. 1981;40:164-72.

23. Yan YM, Coffin JM. Efficient autointegration of avian retrovirus DNA in vitro. J Virol. 1990;64:5958-65.
24. Yan N, Cherepanov P, Daigle JE, et al. The SET complex acts as a barrier to autointegration of HIV-1. PLoS Pathog. 2009;5:e1000327.

25. Lesbats P, Engelman AN, Cherepanov P. Retroviral DNA integration. Chem Rev. 2016;116:12730-57.

26. Delelis $\mathrm{O}$, Parissi $\mathrm{V}$, Leh $\mathrm{H}$, et al. Efficient and specific internal cleavage of a retroviral palindromic DNA sequence by tetrameric HIV-1 integrase. PLoS ONE. 2007:2(7):e608.

27. Munir S, Thierry S, Subra F, et al. Quantitative analysis of the time-course of viral DNA forms during the HIV-1 life cycle. Retrovirology. 2013;10:87.

28. Vatakis DN, Bristol G, Wilkinson TA, et al. Immediate activation fails to rescue efficient human immunodeficiency virus replication in quiescent CD4+ T cells. J Virol. 2007;81:3574-82.

29. Badralmaa Y, Natarajan V. Impact of the DNA extraction method on 2-LTR DNA circle recovery from HIV-1 infected cells. J Virol Methods. 2013;193:184-9.

30. Olivares I, Sánchez-Jiménez C, Vieira CR, et al. Evidence of ongoing replication in a human immunodeficiency virus type 1 persistently infected cell line. J Gen Virol. 2013:94:944-54.

31. Sonza S, Kiernan RE, Maerz AL, et al. Accumulation of unintegrated circular viral DNA in monocytes and growth-arrested T cells following infection with HIV-1. J Leukoc Biol. 1994;56:289-93.

32. Bayer M, Kantor B, Cockrell A, et al. A large U3 deletion causes increased in vivo expression from a nonintegrating lentiviral vector. Mol Ther. 2008;16:1968-76.

33. Kumar A, Herbein G. The macrophage: a therapeutic target in HIV-1 infection. Mol Cell Ther. 2014;2:10.

34. Cara A, Reitz MS Jr. New insight on the role of extrachromosomal retroviral DNA. Leukemia. 1997;11:1395-9.

35. Guntaka RV, Richards OC, Shank PR, et al. Covalently closed circular DNA of avian sarcoma virus: purification from nuclei of infected quail tumor cells and measurement by electron microscopy and gel electrophoresis. J Mol Biol. 1976;106:337-57.

36. Shank $P$, Hughes $S$, Kung $H$, et al. Mapping unintegrated avian sarcoma virus DNA: termini of linear DNA bear 300 nucleotides present once or twice in two species of circular DNA. Cell. 1978;15:1383-95.

37. Pang S, Koyanagi Y, Miles $S$, et al. High levels of unintegrated HIV-1 DNA in brain tissue of AIDS dementia patients. Nature. 1990;343:85-9.

38. Casabianca A, Orlandi C, Canovari B, et al. A real time PCR platform for the simultaneous quantification of total and extrachromosomal HIV DNA forms in blood of HIV-1 infected patients. PLOS ONE. 2014;9:e111919.

39. Meyerhans A, Breinig T, Vartanian J, et al. Forms and function of intracellular HIV DNA. In: Leitner T, Foley B, Hahn B, Marx P, McCutchan F, Mellors JW, Wolinsky S, Korber B, editors. HIV sequence compendium 2003. Los Alamos: Theoretical Biology and Biophysics Group; 2004. p. 14-21.

40. Gelderblom HC, Vatakis DN, Burke SA, et al. Viral complementation allows HIV-1 replication without integration. Retrovirology. 2008;5:60.

41. Butler SL, Hansen MS, Bushman FD. A quantitative assay for HIV DNA integration in vivo. Nat Med. 2001;7:631-4.

42. Vandegraaff N, Kumar R, Burrell CJ, et al. Kinetics of human immunodeficiency virus type 1 (HIV) DNA integration in acutely infected cells as determined using a novel assay for detection of integrated HIV DNA. J Virol. 2001:75:11253-60.

43. Lee MS, Craigie R. Protection of retroviral DNA from autointegration: involvement of a cellular factor. Proc Natl Acad Sci USA. 1994:91:9823-7.

44. Stetson DB, Medzhitov R. Recognition of cytosolic DNA activates an IRF3-dependent innate immune response. Immunity. 2006:24:93-103.

45. Gillim-Ross L, Cara A, Klotman ME. HIV-1 extrachromosomal 2-LTR circular DNA is long-lived in human macrophages. Viral Immunol. 2005:18:190-6.

46. Butler SL, Johnson EP, Bushman FD. Human immunodeficiency virus cDNA metabolism: notable stability of two-long terminal repeat circles. J Virol. 2002:76:3739-47.

47. Kantor B, Ma H, Webster-Cyriaque J, et al. Epigenetic activation of unintegrated HIV-1 genomes by gut-associated short chain fatty acids and its implications for HIV infection. Proc Natl Acad Sci USA. 2009;106:18786-91.

48. Ruis BL, Fattah KR, Hendrickson EA. The catalytic subunit of DNA-dependent protein kinase regulates proliferation, telomere length, and genomic stability in human somatic cells. Mol Cell Biol. 2008;28:6182-95.

49. Collis SJ, DeWeese TL, Jeggo PA, et al. The life and death of DNA-PK. Oncogene. 2005:24:949-61. 
50. Shoemaker C, Goff S, Gilboa E, et al. Structure of a cloned circular Moloney murine leukemia virus DNA molecule containing an inverted segment: implications for retrovirus integration. Proc Natl Acad Sci USA. 1980;77:3932-6.

51. Jeanson L, Subra F, Vaganay S, et al. Effect of Ku80 depletion on the preintegrative steps of HIV-1 replication in human cells. Virology. 2002;300:100-8.

52. Zheng $Y, A o Z$, Wang $B$, et al. Host protein Ku70 binds and protects HIVintegrase from proteasomal degradation and is required for HIV replication. J Biol Chem. 2011;286:17722-35.

53. Pierson TC, Kieffer TL, Ruff CT, et al. Intrinsic stability of episomal circles formed during human immunodeficiency virus type 1 replication. J Virol. 2002;76:4138-44.

54. Swiggard WJ, O'Doherty U, McGain D, et al. Long HIV type 1 reverse transcripts can accumulate stably within resting CD4+ T cells while short ones are degraded. AIDS Res Hum Retroviruses. 2004;20:285-95.

55. Zhou Y, Zhang H, Siliciano JD, et al. Kinetics of human immunodeficiency virus type 1 decay following entry into resting CD4+ T cells. J Virol. 2005;79:2199-210.

56. Bell P, Montaner LJ, Maul GG. Accumulation and intranuclear distribution of unintegrated human immunodeficiency virus type 1 DNA. J Virol. 2001;75:7683-91.

57. Zennou V, Petit C, Guetard D, et al. HIV-1 genome nuclear import is mediated by a central DNA flap. Cell. 2000;101:173-85.

58. Brin E, Yi J, Skalka AM, et al. Modeling the late steps in HIV-1 integrasecatalyzed DNA integration. J Biol Chem. 2000;275:39287-95.

59. Mulder LC, Chakrabarti LA, Muesing MA. Interaction of HIV-1 integrase with DNA repair protein hRad18. J Biol Chem. 2002;277:27489-93.

60. McDermott JL, Martini I, Ferrari D, et al. Decay of human immunodeficiency virus type 1 unintegrated DNA containing two long terminal repeats in infected individuals after 3 to 8 years of sustained control of viremia. J Clin Microbiol. 2005;43:5272-4.

61. Nakajima N, Lu R, Engelman A. Human immunodeficiency virus type 1 replication in the absence of integrase-mediated DNA recombination: definition of permissive and nonpermissive T-cell lines. J Virol. 2001;75:7944-55.

62. Stein J, Storcksdieck Genannt Bonsmann M, Streeck H. Barriers to HIV cure. HLA. 2016;88:155-63.

63. Graf EH, Mexas AM, Yu JJ, et al. Elite suppressors harbor low levels of integrated HIV DNA and high levels of 2-LTR circular HIV DNA compared to HIV+ patients on and off HAART. PLoS Pathog. 2011;7:e1001300.

64. Buzon MJ, Seiss K, Weiss R, et al. Inhibition of HIV-1 integration in ex vivoinfected CD4 T cells from elite controllers. J Virol. 2011;85:9646-50.

65. Sloan RD, Donahue DA, Kuhl BD, et al. Expression of Nef from unintegrated HIV-1 DNA downregulates cell surface CXCR4 and CCR5 on T-lymphocytes. Retrovirology. 2010;7:44.
66. Thierry S, Thierry E, Subra F, et al. Opposite transcriptional regulation of integrated vs unintegrated HIV genomes by the NF-kB pathway. Sci Rep. 2016;6:25678

67. Saenz DT, Loewen N, Peretz M, et al. Unintegrated lentivirus DNA persistence and accessibility to expression in nondividing cells: analysis with class I integrase mutants. J Virol. 2004;78:2906-20.

68. Vargas J Jr, Gusella GL, Najfeld V, et al. Novel integrase-defective lentiviral episomal vectors for gene transfer. Hum Gene Ther. 2004;15:361-72.

69. Yáñez-Muñoz RJ, Balaggan KS, MacNeil A, et al. Effective gene therapy with nonintegrating lentiviral vectors. Nat Med. 2006;12:348-53.

70. Lu R, Nakajima N, Hofmann W, et al. Simian virus 40-based replication of catalytically inactive human immunodeficiency virus type 1 integrase mutants in nonpermissive T cells and monocyte-derived macrophages. J Virol. 2004;78:658-68.

71. Brussel A, Sonigo P. Evidence for gene expression by unintegrated human immunodeficiency virus type 1 DNA species. J Virol. 2004;78:11263-71.

72. Shimura K, Miyazato P, Oishi S, et al. Impact of HIV-1 infection pathways on susceptibility to antiviral drugs and on virus spread. Virology. 2015;484:364-76.

73. Engelman A, Englund G, Orenstein JM, et al. Multiple effects of mutations in human immunodeficiency virus type 1 integrase on viral replication. J Virol. 1995;69:2729-36.

74. Poon B, Chang M, Chen I. Vpr is required for efficient Nef expression from unintegrated human immunodeficiency virus type 1 DNA. J Virol. 2007;81:10515-23.

75. Emeagwali N, Hildreth JE. Human immunodeficiency virus type $1 \mathrm{Vpu}$ and cellular TASK proteins suppress transcription of unintegrated HIV-1 DNA. Virol J. 2012;9:277.

76. Iyer SR, Yu D, Biancotto A, et al. Measurement of human immunodeficiency virus type 1 preintegration transcription by using Rev-dependent Rev-CEM cells reveals a sizable transcribing DNA population comparable to that from proviral templates. J Virol. 2009;83:8662-73.

77. Delelis $\mathrm{O}$, Petit $\mathrm{C}$, Leh $\mathrm{H}$, et al. A novel function for spumaretrovirus integrase: an early requirement for integrase-mediated cleavage of 2 LTR circles. Retrovirology. 2005;2:31.

78. Thierry S, Munir S, Thierry E, et al. Integrase inhibitor reversal dynamics indicate unintegrated HIV-1 dna initiate de novo integration. Retrovirology. 2015;12:24.

79. Poon B, Chen I. Human immunodeficiency virus type 1 (HIV-1) Vpr enhances expression from unintegrated HIV-1 DNA. J Virol. 2003;77:3962-72.

80. Rouzioux C, Richman D. How to best measure HIV reservoirs? Current opinion in HIV and AIDS. 2013;8(3):170-5.

81. Bushman F. Measuring covert HIV replication during HAART: the abundance of 2-LTR circles is not a reliable marker. AIDS. 2003;17:749-50.

82. Rivière L, Darlix J-L, Cimarelli A. Analysis of the Viral Elements Required in the Nuclear Import of HIV-1 DNA. J Virol. 2010;84:729-39.

\section{Submit your next manuscript to BioMed Central and we will help you at every step:}

- We accept pre-submission inquiries

- Our selector tool helps you to find the most relevant journal

- We provide round the clock customer support

- Convenient online submission

- Thorough peer review

- Inclusion in PubMed and all major indexing services

- Maximum visibility for your research

Submit your manuscript at www.biomedcentral.com/submit
BioMed Central 